\title{
Aprendiendo del tiempo de la COVID-19
}

\author{
Learning from the time of the COVID-19
}

\section{Aprendendo com o tempo do COVID-19}

\author{
Julio Cabero-Almenara \\ Universidad de Sevilla \\ Sevilla, España \\ cabero@us.es \\ https://orcid.org/0000-0002-1133-6031
}

Resumen: Se analizan diferentes situaciones problemáticas que han surgido de la situación de la COVID-19 y que deben llevarnos a replantearnos las acciones futuras de enseñanza.

Palabras claves: COVID-19, formación virtual, competencia digital.

Abstract: Different problematic situations that have arisen from the COVID-19 situation are analyzed, which should lead us to rethink future teaching actions.

Keywords: COVID-19, virtual training, digital competence.

Resumo: São analisadas diferentes situações problemáticas que surgiram da situação de COVID-19, o que deve nos levar a repensar futuras ações de ensino.

Palavras-chave: COVID-19, treinamento virtual, competência digital.

Recibido: 05/08/2020 Aceptado: 10/08/2020

\section{Introducción}

La pandemia nos llevó a cambiar el sistema educativo de forma rápida y urgente, y sabemos que las cosas no serán nunca como antes, y lo que debemos hacer es aprender de la situación para mejorar la enseñanza. Rápidamente y sin darnos cuenta la pandemia transformó nuestro sistema educativo, desde modelos fuertemente centrados en una concepción transmisora de información y en la presencialidad docente-discente, a un modelo fuertemente centrado y mediado por las tecnologías. Lo cual supuso un gran reto para todos los actores intervinientes en la educación ya que la formación a distancia rompe con tres variables de la educación presencial: unidad de tiempo, de espacio y de acción. Y ello supuso la aparición y superación de una serie de problemas sobre los que pretendo reflexionar en esta editorial. 
https://doi.org/10.15359/ree.24-S.2

https://www.revistas.una.ac.cr/index.php/educare

educare@una.ac.cr

\section{Desarrollo}

El primero de ellos fue el imaginario social que en algunos sectores educativos se ha creado sobre la formación virtual, presentándola como una formación de segunda categoría respecto a la presencial, y como sabemos las creencias que los docentes tengan sobre la enseñanza, condiciona cómo se comporta en ella. Lo importante no es que la formación sea presencial o a distancia, sino que sea de calidad; una cuestión es la distancia física y otra la cognitiva, y lo que repercute en la calidad de la formación es que la segunda sea mínima. Y ello se puede garantizar con las diferentes herramientas de comunicación sincrónicas y asincrónicas que puede movilizar el docente en la formación virtual. Lo importante, como sugirieron en su momento Garrison y Anderson (2005), es que el docente garantice tres tipos de presencia en la formación virtual: cognitiva, social y de enseñanza.

Otro de los problemas ha sido la baja competencia digital mostrada por algunos docentes para la incorporación educativa de las tecnologías. Aspecto que debe abordarse de forma urgente, pues el modelo en el que trabajaremos en un futuro cercano será mixto, y lo que ha demostrado la situación de la COVID-19, es que muchos profesores lo único que han sabido hacer es repetir en lo virtual lo que realizaban en lo presencial, y abusar de las videoconferencias, con el error adicional de no saber ponderar el volumen de información y actividades que transmitían y exigían a sus estudiantes. Perdiendo de esta forma todas las posibilidades que la tecnología le ofrecía para la realización de e-actividades por parte de los estudiantes, para el trabajo con diferentes tipos de recursos y sistemas simbólicos, y la realización de acciones formativas colaborativas. Ahora bien, la cuestión no es hacer formación del profesorado en TIC, sino abordarla desde ópticas diferentes a como se ha venido realizando (Cabero Almenara y Martínez Gimeno, 2019), centrándonos más en aspectos didácticos y metodológicos y menos en instrumentales y tecnológicos.

Pero también, la pandemia ha ampliado las desigualdades educativas, no todo el estudiantado ha tenido recursos en sus casas ni ha tenido conexiones a internet estable y de calidad para seguir el proceso formativo. La transformación hacia lo on-line y su adaptación ha sido más fácil para unos estudiantes que para otros, y el estudiantado económicamente más favorecido se ha visto más beneficiando, ampliándose de esta forma la brecha social. De ahí que se hace necesario que los gobiernos empiecen a adoptar medidas para solucionar dicho problema, y para que, por una parte, desde un punto de vista educativo, no se olviden otras tecnologías utilizadas en otros momentos en la formación a distancia, como la radio y la televisión y, por otra parte, se facilite y mejoren las conexiones a internet de la ciudadanía.

La importancia que en esta situación ha tenido la tecnología, nos puede llevar a caer en el error de creer que todo lo resolveremos con mayor presencia tecnológica. Y la misma es necesaria, pero también debemos abordar el redefinir el papel del docente en estos nuevos 
https://doi.org/10.15359/ree.24-S.2

contextos formativos mediados por las tecnologías. Donde posiblemente ya no sea tan importante su papel como transmisor o transmisora de información, y otros, como el de diseño de situaciones mediadas de aprendizaje, de tutoría-orientación y de curadororía de contenidos; adquieran mayor relevancia.

Pero también, es necesario replantearnos ese mito de nativos y emigrantes digitales, que ha situado al estudiantado, como altamente competente para el manejo de las tecnologías. Lo pasado ha demostrado que no son tan competentes como algunos autores han defendido, y que han tenido problemas para adaptarse a situaciones de aprendizaje mediadas por las tecnologías, entre otros motivos porque en estas situaciones deben tener una fuerte competencia para autorregular su aprendizaje.

\section{Conclusión}

La situación producida por la COVID-19, nos ha ofrecido una oportunidad para comprender que otra modalidad de formación es posible, pero que para ello deberemos reflexionar sobre diferentes aspectos que van desde la formación en competencias digitales de profesores y estudiantes, la transformación de los roles docentes y el garantizar la equidad social de acceso a las tecnologías.

Nota general: Corrección de estilo y traducciones a cargo del autor.

\section{Referencias}

Cabero Almenara, J. y Martínez Gimeno, A. (2019). Las tecnologías de la información y comunicación y la formación inicial de los docentes. Modelos y competencias digitales. Profesorado. Revista de currículum y formación del profesorado, 23(3), 247-268. https://doi. org/10.30827/profesorado.v23i3.9421

Garrison, D.R. y Anderson, T. (2005). El e-learning en el siglo XXI. Investigación y práctica. Octaedro. 